\title{
Mutations Affecting Mammalian Aging: GH and GHR vs IGF-1 and Insulin
}

\author{
Andrzej Bartke ${ }^{1 *}$ and Holly Brown-Borg ${ }^{2}$ \\ ${ }^{1}$ Department of Internal Medicine, Southern Illinois University School of Medicine, Springfield, IL, United States, ${ }^{2}$ Department of \\ Biomedical Sciences, University of North Dakota School of Medicine and Health Sciences, Grand Forks, ND, United States
}

Keywords: insulin/insulin-like growth factor signaling, mammalian aging, growth hormone, lifespan, healthspan

OPEN ACCESS

Edited by:

Michael Rera,

Centre de Recherches

Interdisciplinaires (CRI), France

Reviewed by:

Adam Salmon,

The University of Texas Health Science Center at San Antonio, United States Jenny C. Regan,

University of Edinburgh, United Kingdom

*Correspondence: Andrzej Bartke abartke@siumed.edu

Specialty section: This article was submitted to Genetics of Aging, a section of the journal

Frontiers in Genetics

Received: 12 February 2021 Accepted: 08 November 2021 Published: 24 November 2021

Citation:

Bartke A and Brown-Borg H (2021) Mutations Affecting Mammalian Aging: $\mathrm{GH}$ and GHR vs IGF-1 and Insulin.

Front. Genet. 12:667355.

doi: 10.3389/fgene.2021.667355
A report of extended longevity in mice homozygous for a mutation producing growth hormone (GH) deficiency (Brown-Borg et al., 1996) was quickly followed by the demonstration of extensive homology between one of the key longevity genes in a worm, Caenorhabditis elegans, and genes coding for insulin and insulin-like growth factor-1 (IGF-1) receptors in mammals (Kimura et al., 1997). Since GH is the key determinant of hepatic IGF-1 expression and circulating IGF-1 levels, and has major impact on insulin signaling (Figure 1), these findings led to an exciting conclusion that the insulin/insulin-like growth factor signaling (IIS) is an evolutionarily conserved mechanism which controls aging in organisms ranging from yeast and worms to insects and mammals. Subsequent work provided much evidence in support of this exciting realization (Tissenbaum and Ruvkun, 1998; Fabrizio et al., 2001; Tatar et al., 2001; Tatar et al., 2003; Piper et al., 2008; Finch and Ruvkun, 2001), and this has led to a focus on IIS, rather than GH signaling, in analyzing genetic control of mammalian aging. This is an important distinction. Although biosynthesis and blood plasma levels of GH and IGF-1 are closely linked, the actions of these hormones are not identical and, in some cases, opposite. For example, IGF-1 mimics some of the insulin actions and promotes insulin sensitivity, while GH is anti-insulinemic and promotes insulin resistance; IGF-1 promotes fat deposition, while GH is lipolytic (Figure 2) (Scavo et al., 2004; Veldhuis et al., 2005; Hu et al., 2009). Actions of GH not shared with IGF-1 include other effects relevant to aging such as impact on reactive radicals production and anti-oxidative defenses (Brown-Borg et al., 2002; Bokov et al., 2009), DNA damage and repair (Chesnokova et al., 2019; Chesnokova and Melmed, 2019), macrophage reprogramming (Schneider et al., 2019), ovarian primordial follicle reserve (Saccon et al., 2017), bone resorption and turnover (Thomas and Monson, 2009), kidney dysfunction (Soliman et al., 2019), and cognitive functioning (Nyberg and Hallberg, 2013).

Evidence for the ability of GH to influence healthspan and lifespan of laboratory mice is very strong and includes significant extension of longevity in both sexes of mice with hypopituitarism (combined deficiency of GH, prolactin, and TSH) (Brown-Borg et al., 1996; Flurkey et al., 2001), in mice with isolated GH deficiency due to mutation of Ghrhr gene or deletion of Ghrh (Flurkey et al., 2001; Sun et al., 2013), and in mice with GH resistance due to Ghr gene disruption (Zhou et al., 1997; Coschigano et al., 2003). This evidence for association of genetically reduced GH signaling with extended longevity was obtained in different laboratories and included animals with different genetic background (Bartke and Turyn, 2001; Coschigano et al., 2003; Aguiar-Oliveira and Bartke, 2019). Importantly, extended longevity of hypopituitary Ames dwarf mice can be reduced by GH replacement therapy during the period of rapid peri-pubertal growth (Panici et al., 2010; Sun et al., 2017). This provides evidence that the association of GH deficiency and increased lifespan in Ames dwarf mice is causal (mechanistic).

In contrast to the remarkable extension of longevity in female and male mice lacking $\mathrm{GH}$ or GH receptors, the impact of reduced IGF-1 signaling on longevity of IGF1R \pm mice and mice treated with an antibody to IGF-1 receptor is modest and seen only in one sex (Holzenberger et al., 2003; Mao 


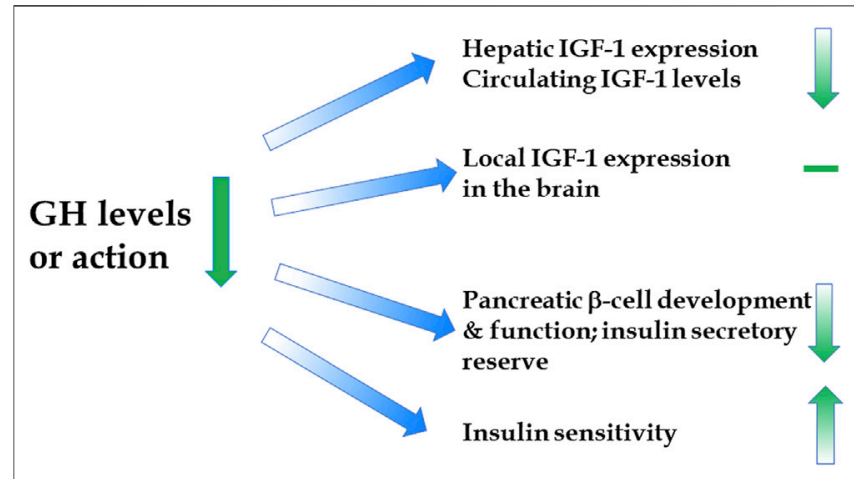

FIGURE 1 | Impact of reduced GH signaling on the levels and actions of IGF-1 and insulin

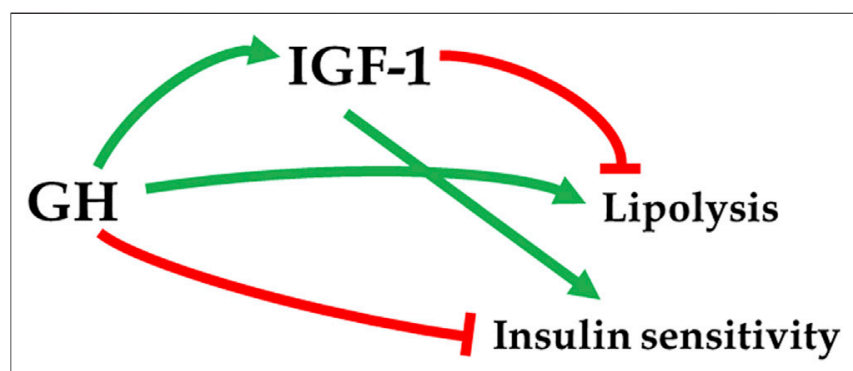

FIGURE 2 | Divergent actions of GH and IGF-1 on metabolic parameters. $\rightarrow$ stimulation; $-\mid$ inhibition. different. Growth hormone promotes insulin resistance acting as a counterregulatory mechanism for hypoglycemia (protection during fasting, food deprivation). While GH counteracts insulin action, IGF-1 enhances insulin sensitivity and mimics some of its actions. Both GH and IGF-1 influence insulin production. When GH levels are reduced, insulin levels are also reduced, whereas IGF-1 inhibits insulin secretion (Haluzik et al., 2003). Another complexity is suggested by the evidence that most of IGF-1's actions on glucose homeostasis and insulin sensitivity are mediated indirectly (through GH suppression), while circulating IGF-1 is bound to high-affinity binding proteins and has low affinity for insulin receptors (Vijayakumar et al., 2011). Direct effects of IGF-1 on glucose management occur mostly in skeletal muscle by increasing glucose uptake (Haluzik et al., 2003; Vijayakumar et al., 2011). Growth hormone influences insulin signaling in liver and adipocytes, whereas no IGF-1 receptors are present in these tissues (Haluzik et al., 2003). Other actions of GH that impact lifespan are also not shared by IGF-1, and thus GH deficiency promotes health and lifespan extension more profoundly than suppression of the levels or action of IGF-1 (Haluzik et al., 2003). Sex-specific responses to suppressing IGF-1 signaling in mice (Ashpole et al., 2017) add to the emerging evidence that, in this species, aging of males is related primarily to the insulin arm of IIS while in females effects of the IGF-1 arm predominate.

In contrast to the findings of extended longevity of IGF-1R heterozygous mice by Holzenberger et al. (Holzenberger et al., 2003), Bokov and his colleagues reported that such animals had very small lifespan extension, no indications of delayed aging, and

TABLE 1 | Effects of reduced IIS and GH signaling on healthspan and lifespan in different taxonomic groups.

\begin{tabular}{|c|c|c|c|c|c|c|}
\hline & & \multirow[t]{2}{*}{ Yeast } & \multirow[t]{2}{*}{ Worms } & \multirow[t]{2}{*}{ Insects } & \multicolumn{2}{|c|}{ Mammals } \\
\hline & & & & & Mice & Humans \\
\hline IIS & healthspan & $?$ & $\uparrow$ & $\uparrow$ & $?$ & $?$ \\
\hline \multirow[t]{2}{*}{$\mathrm{GH}$} & healthspan & NA & NA & NA & $\uparrow$ & $\uparrow$ \\
\hline & lifespan & NA & NA & NA & $\uparrow$ & - \\
\hline
\end{tabular}

et al., 2018; Garratt et al., 2017) (Table 1). This difference between the effects of reduced IGF-1 and GH signaling is likely related to IGF-1 exerting both beneficial and detrimental effects on aging and age-related disease (including opposite effects on the risk of type 2 diabetes vs cardiovascular disease and cognitive decline) and GH having primarily "pro-aging" effects. Both hormones impact growth, but the metabolic effects of $\mathrm{GH}$ are significantly greater. Growth hormone has different and more potent effects on glucose regulation when compared to IGF-1. Growth hormone is a regulator of IGF-1 by controlling much of its production and release from the liver and other tissues, and thus regulating plasma concentrations of IGF-1 (Haluzik et al., 2003; Vijayakumar et al., 2011). Liver-derived IGF-1 represents $>75 \%$ of the circulating hormone (Haluzik et al., 2003; Aguirre et al., 2016). In contrast to the effects on somatic growth, the effects of GH and IGF-1 on glucose homeostasis are markedly no changes in end-of-life pathology (Bokov et al., 2011). Discrepancies between the results of a loss of one IGF-1R allele in these two studies were subsequently shown to be related to differences in constitutive IGF-1 signaling and in endocrine responses to reducing the number of IGF-1 receptors in the employed strains of mice (Xu et al., 2014). In further contrast between the effects of suppressing GH and IGF-1 signaling, complete (homologous) disruption of Igf1 or Igf1r genes can have severe detrimental effects on development, postnatal survival and fertility (Liu et al., 1993; Powell-Braxton et al., 1993; Yakar et al., 1999), while GH-deficient and GHresistant mice are viable and fertile.

Reduced insulin levels and improved insulin sensitivity are associated with extension of longevity in response to calorie restriction or disruption of $\mathrm{GH}$ signaling. However, the effects of genetic alterations of insulin levels, global or organ-specific 
insulin sensitivity, or early steps of intracellular insulin signaling on longevity of laboratory mice are not consistent. Interpretation of the available data is complicated by the negative regulation of expression of the insulin receptors by insulin and by indications that insulin resistance can have both detrimental and protective effects (Barzilai et al., 2012). Templeman and her colleagues reported an 11 percent increase in median longevity of female Ins $2^{+/-}$Ins $1^{-/-}$mice in which insulin levels are reduced by approximately 30 percent (Templeman et al., 2017). This association of improved insulin sensitivity and longevity was also seen in other mutants (Masternak et al., 2009; Zhang et al., 2012), but was absent or reversed in others (Shimizu et al., 2011; Nelson et al., 2012; Takeda et al., 2017). Deletion of Insulin receptor substrate 1 (Irs1) extended longevity, but the effects of Irs2 deletion were not consistent in different studies, likely due to difference in the composition of the diet used in the two laboratories (Taguchi et al., 2007; Selman et al., 2008).

Reports of GH signaling and lifespan in rats are very limited. Spontaneous dwarf rats exhibit reduced GH and IIS signaling and longer lifespans compared to controls (Kuramoto et al., 2010; Sasaki et al., 2013). GH-deficient rats generated by antisense GH gene suppression ( \pm ) also live $7 \%$ longer, but $-/-$ animals do not (Shimokawa et al., 2002). Lewis dwarf rats do not live longer, but are not profoundly GH/IGF-1 deficient ( $55 \%$ reduced), exhibit additional endocrine abnormalities (i.e. hyporesponsive HPA axis), and a general tendency towards pro-inflammation resulting in nephropathy and intracerebral hemorrhage, among other issues (Perretti et al., 1993; Oitzl et al., 1995; Sonntag et al., 2005; Ungvari et al., 2010; Groeneweg et al., 2011; Ungvari et al., 2011; Podlutsky et al., 2017).

Collectively, the available evidence suggests that in addition to the evolutionarily conserved role of IIS in the control of aging, $\mathrm{GH}$ (which has no known homologs in invertebrates) emerges as a major regulator of aging and longevity in mammals. Alterations in IIS in long-lived GH signaling-related mutants represent some

\section{REFERENCES}

Aguiar-Oliveira, M. H., and Bartke, A. (2019). Growth Hormone Deficiency: Health and Longevity. Endocr. Rev. 40 (2), 575-601. doi:10.1210/er.201800216

Aguirre, G. A., De Ita, J. R., de la Garza, R. G., and Castilla-Cortazar, I. (2016). Insulin-like Growth Factor-1 Deficiency and Metabolic Syndrome. J. Transl Med. 14 (1), 3. doi:10.1186/s12967-015-0762-z

Ashpole, N. M., Logan, S., Yabluchanskiy, A., Mitschelen, M. C., Yan, H., Farley, J. A., et al. (2017). IGF-1 Has Sexually Dimorphic, Pleiotropic, and Timedependent Effects on Healthspan, Pathology, and Lifespan. Geroscience 39 (2), 129-145. doi:10.1007/s11357-017-9971-0

Bartke, A. (2020). Growth Hormone and Aging. Rev. Endocr. Metab. Disord. 22 (1), 71-80. doi:10.1007/s11154-020-09593-2

Bartke, A., and Turyn, D. (2001). Mechanisms of Prolonged Longevity: Mutants, Knock-Outs, and Caloric Restriction. J. Anti-Aging Med. 4 (3), 197-203. doi:10.1089/109454501753249966

Barzilai, N., Huffman, D. M., Muzumdar, R. H., and Bartke, A. (2012). The Critical Role of Metabolic Pathways in Aging. Diabetes 61 (6), 1315-1322. doi:10.2337/ db11-1300

Bengtsson, B. A., Edén, S., Ernest, I., Odén, A., and Sjögren, B. (1988). Epidemiology and Long-Term Survival in Acromegaly. A Study of 166 of the multiple mechanisms believed to link GH deficiency or resistance with increases in the healthspan and lifespan (AguiarOliveira and Bartke, 2019).

In humans, the impact of $\mathrm{GH}$ and growth/anabolic processes on longevity is more subtle than in laboratory mice, likely reflecting major differences in the pace-of-life including the reproductive strategies (Aguiar-Oliveira and Bartke, 2019; Bartke, 2020). Genetic syndromes of GH deficiency or resistance do not extend human longevity, even though some individuals with these mutations can reach very advanced age (Aguiar-Oliveira and Bartke, 2019). However, pathological excess of GH reduces life expectancy in both humans and mice (Bengtsson et al., 1988; Steger et al., 1993; Wolf et al., 1993) and familial longevity was shown to be associated with reduced GH secretion (van der Spoel et al., 2016). Intriguingly, there is considerable overlap of phenotypic and metabolic consequences of genetic disruption of $\mathrm{GH}$ signaling in mice and humans (Aguiar-Oliveira and Bartke, 2019), and humans with these syndromes show a remarkable degree of protection from several age-associated chronic diseases along with indications of extended healthspan, that is "healthy aging" (Guevara-Aguirre et al., 2011; AguiarOliveira and Bartke, 2019).

\section{AUTHOR CONTRIBUTIONS}

Article concept and design, AB. Writing of manuscript, AB, HBB. Approval of final manuscript, AB.

\section{FUNDING}

William E. McElroy Charitable Foundation, NIH R21AG062985, and American Diabetes Association 1-19-IBS-126 to AB and NIH R56AG067724 to HB-B.

Cases Diagnosed between 1955 and 1984. Acta Med. Scand. 223 (4), 327-335. doi:10.1111/j.0954-6820.1988.tb15881.x

Bokov, A. F., Garg, N., Ikeno, Y., Thakur, S., Musi, N., DeFronzo, R. A., et al. (2011). Does Reduced IGF-1R Signaling in Igf1r+/- Mice Alter Aging. PLoS One 6 (11), e26891. doi:10.1371/journal.pone.0026891

Bokov, A. F., Lindsey, M. L., Khodr, C., Sabia, M. R., and Richardson, A. (2009). Long-lived ames dwarf Mice Are Resistant to Chemical Stressors. J. Gerontol. A. Biol. Sci. Med. Sci. 64A (8), 819-827. doi:10.1093/gerona/glp052

Brown-Borg, H. M., Borg, K. E., Meliska, C. J., and Bartke, A. (1996). Dwarf Mice and the Ageing Process. Nature 384, 33. doi:10.1038/384033a0

Brown-Borg, H. M., Rakoczy, S. G., Romanick, M. A., and Kennedy, M. A. (2002). Effects of Growth Hormone and Insulin-like Growth Factor-1 on Hepatocyte Antioxidative Enzymes. Exp. Biol. Med. (Maywood) 227 (2), 94-104. doi:10.1177/153537020222700203

Chesnokova, V., and Melmed, S. (2019). Growth Hormone in the Tumor Microenvironment. Arch. Endocrinol. Metab. 63 (6), 568-575. doi:10.20945/ 2359-3997000000186

Chesnokova, V., Zonis, S., Barrett, R. J., Gleeson, J. P., and Melmed, S. (2019). Growth Hormone Induces Colon DNA Damage Independent of IGF-1. Endocrinology 160 (6), 1439-1447. doi:10.1210/en.2019-00132

Coschigano, K. T., Holland, A. N., Riders, M. E., List, E. O., Flyvbjerg, A., and Kopchick, J. J. (2003). Deletion, but Not Antagonism, of the Mouse Growth Hormone Receptor Results in Severely Decreased Body Weights, Insulin, and 
Insulin-like Growth Factor I Levels and Increased Life Span. Endocrinology 144 (9), 3799-3810. doi:10.1210/en.2003-0374

Fabrizio, P., Pozza, F., Pletcher, S. D., Gendron, C. M., and Longo, V. D. (2001). Regulation of Longevity and Stress Resistance by Sch9 in Yeast. Science 292 (5515), 288-290. doi:10.1126/science.1059497

Finch, C. E., and Ruvkun, G. (2001). The Genetics of Aging. Annu. Rev. Genom. Hum. Genet. 2, 435-462. doi:10.1146/annurev.genom.2.1.435

Flurkey, K., Papaconstantinou, J., Miller, R. A., and Harrison, D. E. (2001). Lifespan Extension and Delayed Immune and Collagen Aging in Mutant Mice with Defects in Growth Hormone Production. Proc. Natl. Acad. Sci. 98 (12), 6736-6741. doi:10.1073/pnas.111158898

Garratt, M., Nakagawa, S., and Simons, M. J. P. (2017). Life-span Extension with Reduced Somatotrophic Signaling: Moderation of Aging Effect by Signal Type, Sex, and Experimental Cohort. J. Gerontol. A. Biol. Sci. Med. Sci. 72 (12), 1620-1626. doi:10.1093/gerona/glx010

Groeneweg, F. L., Karst, H., de Kloet, E. R., and Joëls, M. (2011). Rapid Nongenomic Effects of Corticosteroids and Their Role in the central Stress Response. J. Endocrinol. 209 (2), 153-167. doi:10.1530/joe-10-0472

Guevara-Aguirre, J., Balasubramanian, P., Guevara-Aguirre, M., Wei, M., Madia, F., Cheng, C. W., et al. (2011). Growth Hormone Receptor Deficiency Is Associated with a Major Reduction in Pro-aging Signaling, Cancer, and Diabetes in Humans. Sci. Transl Med. 3 (70), 70ra13, 2011 . 70ra13. doi:10.1126/scitranslmed.3001845

Haluzik, M., Yakar, S., Gavrilova, O., Setser, J., Boisclair, Y., and LeRoith, D. (2003). Insulin Resistance in the Liver-specific IGF-1 Gene-Deleted Mouse Is Abrogated by Deletion of the Acid-Labile Subunit of the IGF-Binding Protein-3 Complex: Relative Roles of Growth Hormone and IGF-1 in Insulin Resistance. Diabetes 52 (10), 2483-2489. doi:10.2337/diabetes.52.10.2483

Holzenberger, M., Dupont, J., Ducos, B., Leneuve, P., Géloën, A., Even, P. C., et al. (2003). IGF-1 Receptor Regulates Lifespan and Resistance to Oxidative Stress in Mice. Nature 421 (6919), 182-187. doi:10.1038/nature01298

Hu, D., Pawlikowska, L., Kanaya, A., Hsueh, W.-C., Colbert, L., Newman, A. B., et al. (2009). Serum Insulin-like Growth Factor-1 Binding Proteins 1 and 2 and Mortality in Older Adults: the Health, Aging, and Body Composition Study. J. Am. Geriatr. Soc. 57 (7), 1213-1218. doi:10.1111/j.1532-5415.2009.02318.x

Kimura, K. D., Tissenbaum, H. A., Liu, Y., and Ruvkun, G. (1997). daf-2 , an Insulin Receptor-like Gene that Regulates Longevity and Diapause in Caenorhabditis elegans. Science 277 (5328), 942-946. doi:10.1126/ science.277.5328.942

Kuramoto, K., Tahara, S., Sasaki, T., Matsumoto, S., Kaneko, T., Kondo, H., et al. (2010). Spontaneous dwarf Rat: a Novel Model for Aging Research. Geriatr. Gerontol. Int. 10 (1), 94-101. doi:10.1111/j.1447-0594.2009.00559.x

Liu, J.-P., Baker, J., Perkins, A. S., Robertson, E. J., and Efstratiadis, A. (1993). Mice Carrying Null Mutations of the Genes Encoding Insulin-like Growth Factor I (Igf-1) and Type 1 IGF Receptor (Igf1r). Cell 75 (1), 59-72. doi:10.1016/s00928674(05)80084-4

Mao, K., Quipildor, G. F., Tabrizian, T., Novaj, A., Guan, F., Walters, R. O., et al. (2018). Late-life Targeting of the IGF-1 Receptor Improves Healthspan and Lifespan in Female Mice. Nat. Commun. 9 (1), 2394. doi:10.1038/s41467-01804805-5

Masternak, M. M., Panici, J. A., Bonkowski, M. S., Hughes, L. F., and Bartke, A. (2009). Insulin Sensitivity as a Key Mediator of Growth Hormone Actions on Longevity. Journals Gerontol. Ser. A: Biol. Sci. Med. Sci. 64A (5), 516-521. doi:10.1093/gerona/glp024

Nelson, J. F., Strong, R., Bokov, A., Diaz, V., and Ward, W. (2012). Probing the Relationship between Insulin Sensitivity and Longevity Using Genetically Modified Mice. J. Gerontol. A. Biol. Sci. Med. Sci. 67 (12), 1332-1338. doi:10.1093/gerona/gls199

Nyberg, F., and Hallberg, M. (2013). Growth Hormone and Cognitive Function. Nat. Rev. Endocrinol. 9 (6), 357-365. doi:10.1038/nrendo.2013.78

Oitzl, M. S., van Haarst, A. D., Sutanto, W., and Ron de Kloet, E. (1995). Corticosterone, Brain Mineralocorticoid Receptors (MRs) and the Activity of the Hypothalamic-Pituitary-Adrenal (HPA) axis: the Lewis Rat as an Example of Increased central MR Capacity and a Hyporesponsive HPA axis. Psychoneuroendocrinology 20 (6), 655-675. doi:10.1016/0306-4530(95) 00003-7
Panici, J. A., Harper, J. M., Miller, R. A., Bartke, A., Spong, A., and Masternak, M. M. (2010). Early Life Growth Hormone Treatment Shortens Longevity and Decreases Cellular Stress Resistance in Long-Lived Mutant Mice. FASEB J. 24 (12), 5073-5079. doi:10.1096/fj.10-163253

Perretti, M., Duncan, G. S., Flower, R. J., and Peers, S. H. (1993). Serum Corticosterone, Interleukin-1 and Tumour Necrosis Factor in Rat Experimental Endotoxaemia: Comparison between Lewis and Wistar Strains. Br. J. Pharmacol. 110 (2), 868-874. doi:10.1111/j.1476-5381.1993.tb13893.x

Piper, M. D. W., Selman, C., McElwee, J. J., and Partridge, L. (2008). Separating Cause from Effect: How Does Insulin/IGF Signalling Control Lifespan in Worms, Flies and Mice. J. Intern. Med. 263 (2), 179-191. doi:10.1111/ j.1365-2796.2007.01906.x

Podlutsky, A., Valcarcel-Ares, M. N., Yancey, K., Podlutskaya, V., Nagykaldi, E., Gautam, T., et al. (2017). The GH/IGF-1 axis in a Critical Period Early in Life Determines Cellular DNA Repair Capacity by Altering Transcriptional Regulation of DNA Repair-Related Genes: Implications for the Developmental Origins of Cancer. Geroscience 39 (2), 147-160. doi:10.1007/ s11357-017-9966-x

Powell-Braxton, L., Hollingshead, P., Warburton, C., Dowd, M., Pitts-Meek, S., Dalton, D., et al. (1993). IGF-I Is Required for normal Embryonic Growth in Mice. Genes Dev. 7 (12B), 2609-2617. doi:10.1101/gad.7.12b.2609

Saccon, T. D., Moreira, F., Cruz, L. A., Mondadori, R. G., Fang, Y., Barros, C. C., et al. (2017). Ovarian Aging and the Activation of the Primordial Follicle reserve in the Long-Lived Ames dwarf and the Short-Lived bGH Transgenic Mice. Mol. Cell Endocrinol. 455, 23-32. doi:10.1016/j.mce.2016.10.015

Sasaki, T., Tahara, S., Shinkai, T., Kuramoto, K., Matsumoto, S., Yanabe, M., et al. (2013). Lifespan Extension in the Spontaneous dwarf Rat and Enhanced Resistance to Hyperoxia-Induced Mortality. Exp. Gerontol. 48 (5), 457-463. doi:10.1016/j.exger.2013.02.015

Scavo, L. M., Karas, M., Murray, M., and Leroith, D. (2004). Insulin-like Growth Factor-I Stimulates Both Cell Growth and Lipogenesis during Differentiation of Human Mesenchymal Stem Cells into Adipocytes. J. Clin. Endocrinol. Metab. 89 (7), 3543-3553. doi:10.1210/jc.2003-031682

Schneider, A., Wood, H. N., Geden, S., Greene, C. J., Yates, R. M., Masternak, M. M., et al. (2019). Growth Hormone-Mediated Reprogramming of Macrophage Transcriptome and Effector Functions. Sci. Rep. 9 (1), 19348. doi:10.1038/ s41598-019-56017-6

Selman, C., Lingard, S., Choudhury, A. I., Batterham, R. L., Claret, M., Clements, M., et al. (2008). Evidence for Lifespan Extension and Delayed Age-Related Biomarkers in Insulin Receptor Substrate 1 Null Mice. FASEB j. 22 (3), 807-818. doi:10.1096/fj.07-9261com

Shimizu, T., Baba, T., Ogawara, M., and Shirasawa, T. (2011). Lifespan and Glucose Metabolism in Insulin Receptor Mutant Mice. J. Aging Res. 2011, 315640. doi:10.4061/2011/315640

Shimokawa, I., Higami, Y., Utsuyama, M., Tuchiya, T., Komatsu, T., Chiba, T., et al. (2002). Life Span Extension by Reduction in Growth Hormone-insulin-like Growth Factor-1 axis in a Transgenic Rat Model. Am. J. Pathol. 160 (6), 2259-2265. doi:10.1016/s0002-9440(10)61173-x

Soliman, A. R., Soliman, M. A., and Sadek, K. M. (2019). Association of Insulin Growth Factor-1 and Growth Hormone Levels in Elderly Renal Transplant Recipients with Cardiac Dysfunction. Saudi J. Kidney Dis. Transpl. 30 (1), $62-67$.

Sonntag, W. E., Carter, C. S., Ikeno, Y., Ekenstedt, K., Carlson, C. S., Loeser, R. F., et al. (2005). Adult-onset Growth Hormone and Insulin-like Growth Factor I Deficiency Reduces Neoplastic Disease, Modifies Age-Related Pathology, and Increases Life Span. Endocrinology 146 (7), 2920-2932. doi:10.1210/en.20050058

Steger, R. W., Bartke, A., and Cecim, M. (1993). Premature Ageing in Transgenic Mice Expressing Different Growth Hormone Genes. J. Reprod. Fertil. Suppl. 46, $61-75$.

Sun, L. Y., Fang, Y., Patki, A., Koopman, J. J., Allison, D. B., Hill, C. M., et al. (2017). Longevity Is Impacted by Growth Hormone Action during Early Postnatal Period. Elife 6. doi:10.7554/eLife.24059

Sun, L. Y., Spong, A., Swindell, W. R., Fang, Y., Hill, C., Huber, J. A., et al. (2013). Growth Hormone-Releasing Hormone Disruption Extends Lifespan and Regulates Response to Caloric Restriction in Mice. Elife 2, e01098. doi:10.7554/eLife.01098 
Taguchi, A., Wartschow, L. M., and White, M. F. (2007). Brain IRS2 Signaling Coordinates Life Span and Nutrient Homeostasis. Science 317 (5836), 369-372. doi:10.1126/science.1142179

Takeda, E., Suzuki, Y., Yamada, T., Katagiri, H., and Sato, Y. (2017). Knockout of Vasohibin-1 Gene in Mice Results in Healthy Longevity with Reduced Expression of Insulin Receptor, Insulin Receptor Substrate 1, and Insulin Receptor Substrate 2 in Their White Adipose Tissue. J. Aging Res. 2017, 9851380. doi:10.1155/2017/9851380

Tatar, M., Bartke, A., and Antebi, A. (2003). The Endocrine Regulation of Aging by Insulin-like Signals. Science 299 (5611), 1346-1351. doi:10.1126/science.1081447

Tatar, M., Kopelman, A., Epstein, D., Tu, M.-P., Yin, C.-M., and Garofalo, R. S. (2001). A Mutant Drosophila Insulin Receptor Homolog that Extends LifeSpan and Impairs Neuroendocrine Function. Science 292 (5514), 107-110. doi:10.1126/science.1057987

Templeman, N. M., Flibotte, S., Chik, J. H. L., Sinha, S., Lim, G. E., Foster, L. J., et al. (2017). Reduced Circulating Insulin Enhances Insulin Sensitivity in Old Mice and Extends Lifespan. Cel Rep. 20 (2), 451-463. doi:10.1016/j.celrep.2017.06.048

Thomas, J. D., and Monson, J. P. (2009). Adult GH Deficiency throughout Lifetime. Eur. J. Endocrinol. 161 Suppl 1 (Suppl. 1), S97-S106. doi:10.1530/EJE-09-0258

Tissenbaum, H. A., and Ruvkun, G. (1998). An Insulin-like Signaling Pathway Affects Both Longevity and Reproduction in Caenorhabditis elegans. Genetics 148 (2), 703-717. doi:10.1093/genetics/148.2.703

Ungvari, Z., Gautam, T., Koncz, P., Henthorn, J. C., Pinto, J. T., Ballabh, P., et al. (2010). Vasoprotective Effects of Life Span-Extending Peripubertal GH Replacement in Lewis dwarf Rats. Journals Gerontol. Ser. A: Biol. Sci. Med. Sci. 65A (11), 1145-1156. doi:10.1093/gerona/glq147

Ungvari, Z., Sosnowska, D., Podlutsky, A., Koncz, P., Sonntag, W. E., and Csiszar, A. (2011). Free Radical Production, Antioxidant Capacity, and Oxidative Stress Response Signatures in Fibroblasts from Lewis dwarf Rats: Effects of Life SpanExtending Peripubertal GH Treatment. Journals Gerontol. Ser. A: Biol. Sci. Med. Sci. 66A (5), 501-510. doi:10.1093/gerona/glr004

van der Spoel, E., Jansen, S. W., Akintola, A. A., Ballieux, B. E., Cobbaert, C. M., Slagboom, P. E., et al. (2016). Growth Hormone Secretion Is Diminished and Tightly Controlled in Humans Enriched for Familial Longevity. Aging Cell 15 (6), 1126-1131. doi:10.1111/acel.12519

Veldhuis, J. D., Iranmanesh, A., and Bowers, C. Y. (2005). Joint Mechanisms of Impaired Growth-Hormone Pulse Renewal in Aging Men. J. Clin. Endocrinol. Metab. 90 (7), 4177-4183. doi:10.1210/jc.2005-0336
Vijayakumar, A., Yakar, S., and Leroith, D. (2011). The Intricate Role of Growth Hormone in Metabolism. Front. Endocrin. 2, 32. doi:10.3389/ fendo.2011.00032

Wolf, E., Kahnt, E., Ehrlein, J., Hermanns, W., Brem, G., and Wanke, R. (1993). Effects of Long-Term Elevated Serum Levels of Growth Hormone on Life Expectancy of Mice: Lessons from Transgenic Animal Models. Mech. Ageing Dev. 68 (1-3), 71-87. doi:10.1016/0047-6374(93)90141-d

Xu, J., Gontier, G., Chaker, Z., Lacube, P., Dupont, J., and Holzenberger, M. (2014). Longevity Effect of IGF-1R+/-mutation Depends on Genetic Backgroundspecific Receptor Activation. Aging Cell 13 (1), 19-28. doi:10.1111/acel.12145

Yakar, S., Liu, J.-L., Stannard, B., Butler, A., Accili, D., Sauer, B., et al. (1999). Normal Growth and Development in the Absence of Hepatic Insulin-like Growth Factor I. Proc. Natl. Acad. Sci. 96 (13), 7324-7329. doi:10.1073/pnas.96.13.7324

Zhang, Y., Xie, Y., Berglund, E. D., Coate, K. C., He, T. T., Katafuchi, T., et al. (2012). The Starvation Hormone, Fibroblast Growth Factor-21, Extends Lifespan in Mice. Elife 1, e00065. doi:10.7554/eLife.00065

Zhou, Y., Xu, B. C., Maheshwari, H. G., He, L., Reed, M., Lozykowski, M., et al. (1997). A Mammalian Model for Laron Syndrome Produced by Targeted Disruption of the Mouse Growth Hormone Receptor/binding Protein Gene (The Laron Mouse). Proc. Natl. Acad. Sci. 94 (24), 13215-13220. doi:10.1073/ pnas.94.24.13215

Conflict of Interest: The authors declare that the research was conducted in the absence of any commercial or financial relationships that could be construed as a potential conflict of interest.

Publisher's Note: All claims expressed in this article are solely those of the authors and do not necessarily represent those of their affiliated organizations, or those of the publisher, the editors and the reviewers. Any product that may be evaluated in this article, or claim that may be made by its manufacturer, is not guaranteed or endorsed by the publisher.

Copyright $\odot 2021$ Bartke and Brown-Borg. This is an open-access article distributed under the terms of the Creative Commons Attribution License (CC BY). The use, distribution or reproduction in other forums is permitted, provided the original author(s) and the copyright owner(s) are credited and that the original publication in this journal is cited, in accordance with accepted academic practice. No use, distribution or reproduction is permitted which does not comply with these terms. 